\title{
Computer-Aided Optimal Design of A Single-Chamber Muffler with Side Inlet/Outlet Under Space Constraints
}

\author{
Long-Jyi Yeh \\ Associate Professor, Department of Mechanical Engineering, Tatung University, 40 Chungshan N. Rd., 3rd Sec., Taipei, \\ Taiwan 104, R.O.C., ljyeh@ttu.edu.tw \\ Ying-Chun Chang \\ Assistant Professor, Department of Mechanical Engineering, Tatung University, 40 Chungshan N. Rd., 3rd Sec., Taipei, \\ Taiwan 104, R.O.C., min-chie.chiu@ctci.com.tw \\ Min-Chie Chiu \\ Student in Ph, D Program, Department of Mechanical Engineering, Tatung University, 40 Chungshan N. Rd., 3rd Sec., \\ Taipei, Taiwan 104, R.O.C., ycchang@ttu.edu.tw \\ Gaung-Jer Lay \\ Professor, Department of Mechanical Engineering, Tatung University, 40 Chungshan N. Rd., 3rd Sec., Taipei, Taiwan \\ 104, R.O.C.
}

Follow this and additional works at: https://jmstt.ntou.edu.tw/journal

Part of the Mechanical Engineering Commons

\section{Recommended Citation}

Yeh, Long-Jyi; Chang, Ying-Chun; Chiu, Min-Chie; and Lay, Gaung-Jer (2003) "Computer-Aided Optimal Design of A Single-Chamber Muffler with Side Inlet/Outlet Under Space Constraints," Journal of Marine Science and Technology. Vol. 11: Iss. 4, Article 2.

DOI: $10.51400 / 2709-6998.2289$

Available at: https://jmstt.ntou.edu.tw/journal/vol11/iss4/2

This Research Article is brought to you for free and open access by Journal of Marine Science and Technology. It has been accepted for inclusion in Journal of Marine Science and Technology by an authorized editor of Journal of Marine Science and Technology. 


\title{
COMPUTER-AIDED OPTIMAL DESIGN OF A SINGLE-CHAMBER MUFFLER WITH SIDE INLET/OUTLET UNDER SPACE CONSTRAINTS
}

\author{
Long-Jyi Yeh*, Ying-Chun Chang**, Min-Chie Chiu*** and Gaung-Jer Lay****
}

Key words: plane wave, four- poles matrices, optimal, single-chamber muffler with side inlet/outlet.

\section{ABSTRACT}

Whilst the muffler dimension is often limited inside a building or machine room, the consideration of maximal sound transmission loss (STL) under space constraints becomes important and essential to the field of acoustics. In this paper, the optimal design of a singlechamber muffler with side inlet/outlet is comprehensively presented. Both the graphic analysis and the computer-aided numerical assessments are also fully described in this study. With the computer graphic analysis on sensitivity, one set of design data is derived primarily, and the numerical searching algorithm of iteration technique and the initial design data are then carried out. These results are then verified with Kuhn-Tucker Condition for accuracy. Furthermore, the simulated results show that the STL of muffler is exactly maximized at the desired frequency. This study demonstrates a quick and economical approach to optimize the design for a single-chamber muffler with side inlet/outlet under space constraints without redundant testing.

\section{INTRODUCTION}

The trial and error method to improve a muffler design of which the muffler dimension is often limited by the machine room is definitely tedious and expensive. Therefore, the interest to optimize sound transmission loss (STL) of the muffler under space constraints is

Paper Submitted 08/12/03, Accepted 11/06/03. Author for Correspondence: Long-JyiYeh.E-mail: ljyeh@ttu.edu.tw

*Associate Professor, Department of Mechanical Engineering, Tatung University, 40 Chungshan N. Rd., 3rd Sec., Taipei, Taiwan 104, R.O.C.

**Assistant Professor, Department of Mechanical Engineering, Tatung University, 40 Chungshan N. Rd., 3rd Sec., Taipei, Taiwan 104, R.O.C. E-mail:min-chie.chiu@ctci.com.tw

***Student in Ph, D Program, Department of Mechanical Engineering, Tatung University, 40 Chungshan N. Rd., 3rd Sec., Taipei, Taiwan 104, R.O.C.E-mail: ycchang@ttu.edu.tw

****Professor, Department of Mechanical Engineering, Tatung University, 40 Chungshan N. Rd., 3rd Sec., Taipei, Taiwan 104, R.O.C. arising on the practical aspect.

Many researches on the muffler design were well developed; however, the discussion of sensitivity between design parameters under space constraints is hardly realized. Bernhard [1] has introduced the shape optimization procedure of simple expansion mufflers, and developed the sensitivity matrices to judge the global maximum. Nevertheless, the space volume of the reactive muffler is still non-constrained, and the calculation of design sensitivity matrices is difficult for the mufflers with complicated mechanism. In addition, the constrained problem is mostly concerned for the necessity of operation and maintenance in practical engineering work. In our previous research [8], an optimal shape design to improve the performance of STL on the constrained single expansion muffler with the aids of computer graphic analysis on sensitivity was discussed. To increase the STL on muffler, a new muffler with side inlet and outlet where the flow direction is transformed perpendicularly is thus considered and discussed in this paper.

This paper may provide a quick method to obtain an optimal design data for a single-chamber muffler through our proposed computer graphic system and the numerical assessment. A numerical case of a singlechamber muffler with side inlet/outlet is illustrated to exemplify the advantages of the shape optimization.

\section{THEORETICAL BACKGROUND}

A 3-D cross-section view of the single-chamber muffler with side inlet/outlet is shown in Figure 1. The flowing condition and location of the muffler are specified in Figure 2, where the whole flow condition within the muffler is presented by eight chosen nodes (pt1 pt8) to deduce the theoretical derivation. For a slender muffler in duct, the higher modes of waves are diminished. Therefore, only the pure plane wave with the lowest mode will be existed. Based on the plane wave theory, four-poles matrices become easier to 
present the sound transmission loss of muffler. The theoretical derivation of four-poles matrices is thus described as follows.

\section{Straight duct $[4,5,6]$}

Using the momentum equation in which the body force and viscosity effect are negligible, the NavierStokes equation is then simplified as

$$
\rho[\partial V / \partial t+V \cdot \nabla V]=-\nabla P
$$

Developing $V, \rho$ and $P$, Eq. (1) is then expressed as

$$
\nabla\left[\rho_{o}\left(\partial \phi / \partial t+V_{o} \partial \phi / \partial x\right)-p\right]=0
$$

The analytical solution for the 1-D partial differential equation (2) is then deduced and obtained as

$$
p=j \omega \rho_{o} \phi+\rho_{o} V_{o} \partial \phi / \partial x
$$

where

$$
\begin{aligned}
& \phi=\left[A e^{-j k_{1} x}+B e^{+j k_{2} x}\right] e^{j \omega t} ; k_{1}=k /(1+M) ; \\
& k_{2}=k /(1-M)
\end{aligned}
$$

Therefore, the four poles matrix between point 1 and point 2 with mean flow is expressed as

$$
\left(\begin{array}{c}
p_{1} \\
\rho_{o} c_{o} u_{1}
\end{array}\right)=e^{-j M_{1} k L_{1} /\left(1-M_{1}^{2}\right)}\left[\begin{array}{ll}
b 11^{*} & b 12^{*} \\
b 21^{*} & b 22^{*}
\end{array}\right]\left(\begin{array}{c}
p_{2} \\
\rho_{o} c_{o} u_{2}
\end{array}\right)
$$

where $b 11^{*}=\cos \left(\frac{k L_{1}}{1-M_{1}^{2}}\right) ; b 12^{*}=j \sin \left(\frac{k L_{1}}{1-M_{1}^{2}}\right)$;

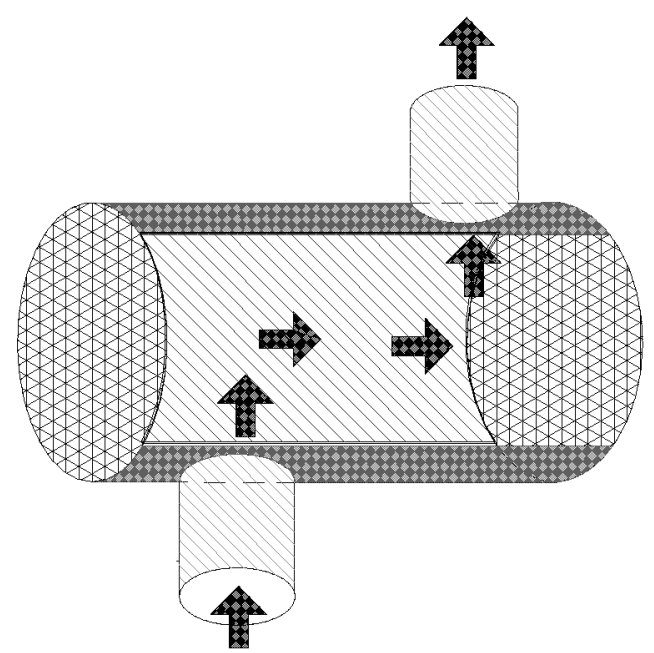

Fig. 1. 3-D cross-section for muffler with side inlet/outlet. $b 21^{*}=j \sin \left(\frac{k L_{1}}{1-M_{1}^{2}}\right) ; b 22^{*}=\cos \left(\frac{k L_{1}}{1-M_{1}^{2}}\right)$

From the derivation in Eq. (4), the four poles matrix between point 4 and point 5 with mean flow is

$$
\left(\begin{array}{c}
p_{4} \\
\rho_{o} c_{o} u_{4}
\end{array}\right)=e^{-j M_{4} k L_{3} /\left(1-M_{4}^{2}\right)}\left[\begin{array}{ll}
c 11^{*} & c 12^{*} \\
c 21^{*} & c 22^{*}
\end{array}\right]\left(\begin{array}{c}
p_{5} \\
\rho_{o} c_{o} u_{5}
\end{array}\right)
$$

where $c 11^{*}=\cos \left(\frac{k L_{3}}{1-M_{4}^{2}}\right) ; c 12^{*}=j \sin \left(\frac{k L_{3}}{1-M_{4}^{2}}\right)$; $c 21^{*}=j \sin \left(\frac{k L_{3}}{1-M_{4}^{2}}\right) ; c 22^{*}=\cos \left(\frac{k L_{3}}{1-M_{4}^{2}}\right)$

Similarly, the four poles matrix between point 7 and point 8 with mean flow is expressed as

$$
\left(\begin{array}{c}
p_{7} \\
\rho_{o} c_{o} u_{7}
\end{array}\right)=e^{-j M_{7} k L_{5} /\left(1-M_{7}^{2}\right)}\left[\begin{array}{ll}
d 11^{*} & d 12^{*} \\
d 21^{*} & d 22^{*}
\end{array}\right]\left(\begin{array}{c}
p_{8} \\
\rho_{o} c_{o} u_{8}
\end{array}\right)
$$

where $d 11^{*}=\cos \left(\frac{k L_{5}}{1-M_{7}^{2}}\right) ; d 12^{*}=j \sin \left(\frac{k L_{5}}{1-M_{7}^{2}}\right)$; $d 21^{*}=j \sin \left(\frac{k L_{5}}{1-M_{7}^{2}}\right) ; d 22^{*}=\cos \left(\frac{k L_{5}}{1-M_{7}^{2}}\right)$

\section{Side inlet/Side outlet duct [3]}

As derived by Munjal [3], the four poles matrix between point 2 and point 4 with mean flow takes the form

$$
\left(\begin{array}{l}
p_{2} \\
v_{2}
\end{array}\right)=\left[\begin{array}{cc}
1-\frac{M_{2} Y_{2}}{Z_{3}}\left(1+k_{e}\right) M_{4} Y_{4}-M_{2} Y_{2}+Y_{2}\left(j 0.85 k D_{1} / 2\right) \\
\frac{1}{Z_{3}} & 1
\end{array}\right]\left(\begin{array}{l}
p_{4} \\
v_{4}
\end{array}\right)
$$

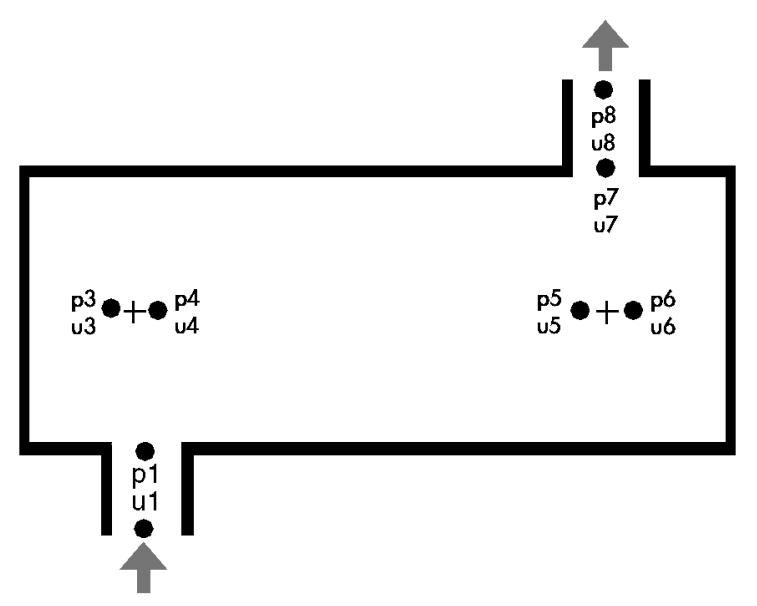

Fig. 2. Flow condition for muffler with side inlet/outlet. 
where $Z_{3}=-j \frac{c_{o}}{S_{3}} \cot \left(k L_{2}\right) ; Y_{3}=Y_{4}=\frac{c_{o}}{S_{4}} ;$

$k_{e}=\left[\left(\frac{S_{4}}{S_{2}}\right)-1\right]^{2}$

Note that instead of the acoustic mass velocity, $v$, the acoustic particle velocity, $u$, is adopted in equation (7). An equivalent form is then derived as $\left(\begin{array}{c}p_{2} \\ \rho_{o} c_{o} u_{2}\end{array}\right)=\left[\begin{array}{c}1-j \frac{M_{2} S_{3}}{S_{2}} \tan \left(k L_{2}\right) \\ j \rho_{o} S_{3} \tan \left(k L_{2}\right)\end{array}\left[\frac{M_{3}}{\rho_{o} S_{3}}\left[1+\left(\frac{S_{4}}{S_{2}}-1\right)^{2}\right]-\frac{M_{2}}{\rho_{O} S_{2}}\right] \frac{S_{4}}{c_{o}}+j\left[\frac{0.85 k D_{1} S_{4}}{2 \rho_{O} S_{2} c_{o}}\right]\right]$

$$
\left(\begin{array}{c}
p_{4} \\
\rho_{o} c_{o} u_{4}
\end{array}\right)
$$

Equation (8) can be expressed in compact form as

$$
\left(\begin{array}{c}
p_{2} \\
\rho_{o} c_{o} u_{2}
\end{array}\right)=[T S 2]\left(\begin{array}{c}
p_{4} \\
\rho_{o} c_{o} u_{4}
\end{array}\right)
$$

where

$[T S 2]=\left[\begin{array}{c}1-j \frac{M_{2} S_{3}}{S_{2}} \tan \left(k L_{2}\right) \\ j \rho_{o} S_{3} \tan \left(k L_{2}\right)\end{array}\left[\frac{M_{3}}{\rho_{o} S_{3}}\left[1+\left(\frac{S_{4}}{S_{2}}-1\right)^{2}\right] \underset{S_{4} / S_{2}}{-\frac{M_{2}}{\rho_{o} S_{2}}}\right] \frac{S_{4}}{c_{o}}+j\left[\frac{0.85 k D_{1} S_{4}}{2 \rho_{o} S_{2} c_{o}}\right]\right]$

As described in Eq. (7), the four poles matrix between point 5 and point 7 with mean flow can be expressed as

$$
\left(\begin{array}{c}
p_{5} \\
\rho_{o} c_{o} u_{5}
\end{array}\right)=[T S 4]\left(\begin{array}{c}
p_{7} \\
\rho_{o} c_{o} u_{7}
\end{array}\right)
$$

where

$[T S 4]=\left[\begin{array}{ll}1-j M_{5} \tan \left(k L_{4}\right) & {\left[\left(\frac{1-S_{7} / S_{5}}{2}+1\right) \frac{M_{7}}{S_{7} \rho_{o}}-\frac{M_{5}}{S_{5} \rho_{o}}\right]\left(\frac{S_{7}}{c_{o}}\right)+j\left[\frac{0.85 k D_{2}}{2 \rho_{o} c_{o}}\right]} \\ j \rho_{o} S_{5} \tan \left(k L_{4}\right) & \frac{S_{7}}{S_{5}}+j\left[\left(\frac{M_{7} S_{5}}{S_{7}}-M_{5}\right) \tan \left(k L_{4}\right)\right]\left(\frac{S_{7}}{S_{5}}\right)\end{array}\right]$

\section{Combination of system matrix}

Through the matrix substitution on equation (4), (5), (6), (9), and (10), one has

$$
\begin{aligned}
& \left(\begin{array}{c}
p_{1} \\
\rho_{o} c_{o} u_{1}
\end{array}\right)=e^{-j k\left(\frac{M_{1} L_{1}}{1-M_{1}^{2}}+\frac{M_{4} L_{3}}{1-M_{4}^{2}}+\frac{M_{7} L_{5}}{1-M_{7}^{2}}\right)}\left[\begin{array}{ll}
b 11^{*} & b 12^{*} \\
b 21^{*} & b 22^{*}
\end{array}\right] \\
& {[T S 2]\left[\begin{array}{ll}
c 11^{*} & c 12^{*} \\
c 21^{*} & c 22^{*}
\end{array}\right][T S 4]\left[\begin{array}{ll}
d 11^{*} & d 12^{*} \\
d 21^{*} & d 22^{*}
\end{array}\right]\left(\begin{array}{c}
p_{8} \\
\rho_{o} c_{o} u_{8}
\end{array}\right)}
\end{aligned}
$$

Eq. (11) can be simplified as

$$
\left(\begin{array}{c}
p_{1} \\
\rho_{o} c_{o} u_{1}
\end{array}\right)=\left[\begin{array}{cc}
T 11^{*} & T 12^{*} \\
T 21^{*} & T 22^{*}
\end{array}\right]\left(\begin{array}{c}
p_{8} \\
\rho_{o} c_{o} u_{8}
\end{array}\right)
$$

The sound transmission loss (STL) [2] of muffler is defined as

$$
\begin{aligned}
S T L & =20 \log \left(\frac{\left|T 11^{*}+T 12^{*}+T 21^{*}+T 22^{*}\right|}{2}\right)+10 \log \left(\frac{S_{1}}{S_{8}}\right) \\
& =f\left(L_{1}, L_{2}, L_{3}, L_{4}, L_{5}, D_{1}, D_{2}, D_{45}\right) \\
& =f(X)
\end{aligned}
$$

\section{CASE STUDY}

The noise control of a diesel engine at the exhausted outlet is introduced as the numerical case in this study. According to the spectrum of sound power level (SWL) shown in Table 1, it reveals that the sound wave at $500 \mathrm{~Hz}$ is remarkable. The available space for silencer is $0.5^{\mathrm{M}} \mathrm{L} \times 0.5{ }^{\mathrm{M}} \mathrm{W} \times 3.0{ }^{\mathrm{M}} \mathrm{H}$, and the O.D. (outside diameter) of exhaust pipe is confined to $0.0762(\mathrm{~m})$. To reduce the sound energy at $500 \mathrm{~Hz}$, an attempt to optimize the design on muffler is then composed under the boundary constraint. Both the graphic analysis and numerical assessments are carried out as follows. The space constraint for muffler is shown in Figure 3, and the design volume flow rate is confined to be $0.8 \mathrm{CMS}$. In order to simplify the optimal process, the length of inlet and outlet tube is assumed to be equal. That is, L1 is equal to L5. Therefore, the design parameters are classified as D1, D2, L2, L3, L4, and D45.

\section{COMPUTER AIDED DESIGN}

\section{Sensitivity Analysis}

\section{(A) D1 and feffect}

STL with respect to D1 and frequency is shown as Figure 4, which reveals that the rise of STL will be found by decreasing the value of D1 at the fixed frequency.

\section{(B) D2 and f effect}

STL with respect to D2 and frequency is shown as Figure 5, which reveals that the rise of STL will be obtained by decreasing the value of D2 at the fixed frequency.

\section{(C) D45 and f effect}

STL with respect to D45 and frequency is shown as

Table 1. The sound power level (SWL)

\begin{tabular}{cccccccccc}
\hline $\mathrm{f}(\mathrm{Hz})$ & 63 & 125 & 250 & 500 & $1 \mathrm{k}$ & $2 \mathrm{k}$ & $4 \mathrm{k}$ & $8 \mathrm{k}$ \\
\hline $\mathrm{SWL}(\mathrm{dB})$ & 90 & 94 & 93 & 104 & 95 & 91 & 88 & 64 \\
\hline
\end{tabular}


Figure 6 which reveals that the lowest value of STL is found at the fixed frequency.

\section{(D) L2 and L4 effect}

At the conditions of D1 $=0.0762(\mathrm{~m}), \mathrm{D} 2=0.0762$ (m) and D45 $=0.3(\mathrm{~m})$, STL with respect to L2 and L4 is shown as Figure $7 \mathrm{a}$ and $7 \mathrm{~b}$, where there exists several peak values of STL along the line of L4 $=1.2(\mathrm{~m})$.

\section{(E) L2 and L3 effect}

At the conditions of D1 $=0.0762(\mathrm{~m}), \mathrm{D} 2=0.0762$ (m) and D45 $=0.3(\mathrm{~m})$, STL with respect to L2 and L3 is shown as Figure $8 \mathrm{a}$ and $8 \mathrm{~b}$ where the peak values occurs along the line of L2 + L3 $=1.8$ nearly.

\section{Discussion of sensitivity}

Based on the analysis in Section 4.1; D1, D2, L2, L3, L4, and D45 are the major parameters with higher sensitivity in STL. However, the STL is inversely proportional to D1 and D2. To maximize STL, the smaller values of D1 and D2 are set as $0.0762(\mathrm{~m})$ which is not less than the outlet diameter of diesel engine to

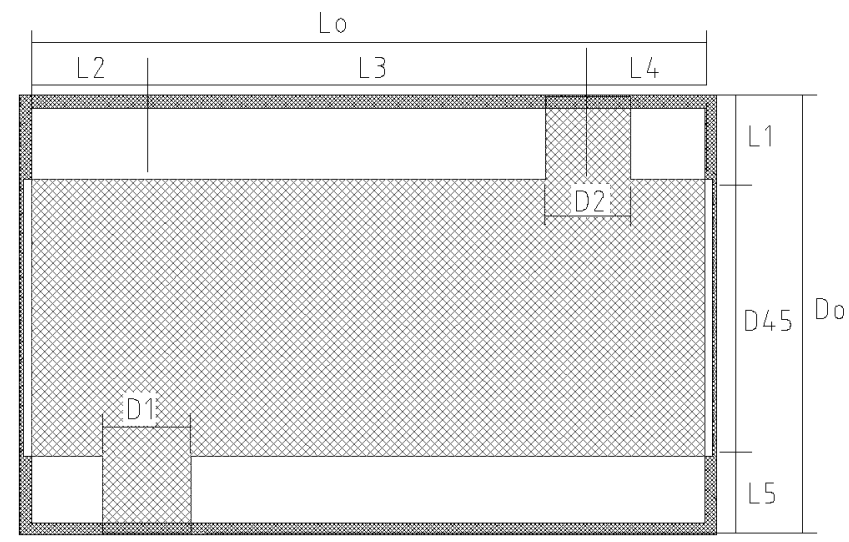

Fig. 3. Space constraints for muffler with side inlet/outlet $[\mathrm{Lo}=3.0 \mathrm{~m}$; Do $=0.5 \mathrm{~m}]$

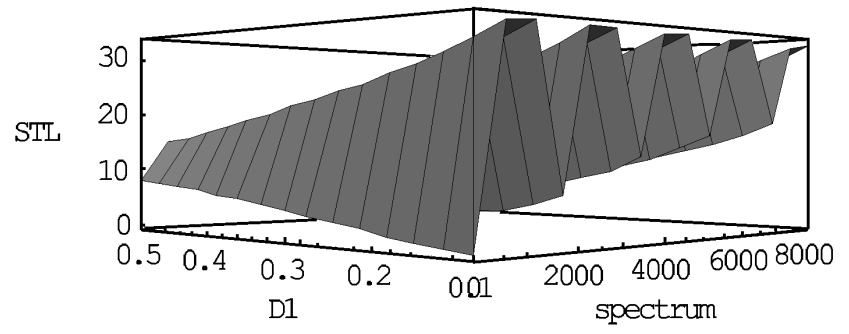

Fig. 4. STL with respect to frequency and D1. release the pressure drop and induced flow noise. In addition, STL will be increased at the increment of D45. Therefore, a lager value of D45 is set to be $0.3(\mathrm{~m})$ of which the rest of L1 and L5 are reserved for conjunction purpose. With the above conditions of D1, D2 and D45, the responses of STL with respect to L2, L3, and D45 at $500 \mathrm{~Hz}$ are shown in Figure $7 \mathrm{a}, \mathrm{b}$ and Figure 8a,b, which reveal that the maximum value of STL occurs along either L $2+\mathrm{L} 3=1.8$ or L4 $=1.2$ where the constrained relationship of $\mathrm{L} 2+\mathrm{L} 3+\mathrm{L} 4=3.0$ exists. Thus, the initial design data are thus decided as D1 $=0.0762(\mathrm{~m})$; $\mathrm{D} 2=0.0762(\mathrm{~m}) ; \mathrm{L} 1=0.1(\mathrm{~m}) ; \mathrm{D} 45=0.3(\mathrm{~m}) ; \mathrm{L} 5=$ $0.1(\mathrm{~m}) ; \mathrm{L} 4=1.2(\mathrm{~m}) ; \mathrm{L} 2+\mathrm{L} 3=1.8(\mathrm{~m})$

\section{NUMERICAL OPTIMAL ASSESSMENT}

For the accuracy purpose in plane wave theory, the shape constraint of a long chamber is required. An assumption is made that the ratios of diameter to length for each segment of pipe are limited to be not less than 2.46 verified by Munjal [3]. To maximize the value of STL, the minimal value of $-f(X)$ is planned and proceeded. The design parameter L2 is chosen and L3 is determined in terms of Lo-L2-L4 during the following numerical optimal process assessment.

\section{Mathematical Formulation [7]}

Minimize $F(X)=-f(X)$, objective function Subject to $g_{j}(X) \leq 0, j=1,2$ inequality constraints where $X=\left[X_{1}\right]=\left[L_{2}\right]$ design variable

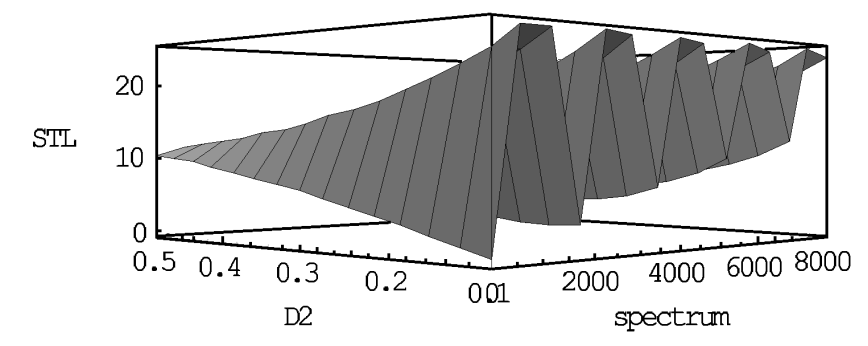

Fig. 5. STL with respect to frequency and D2.

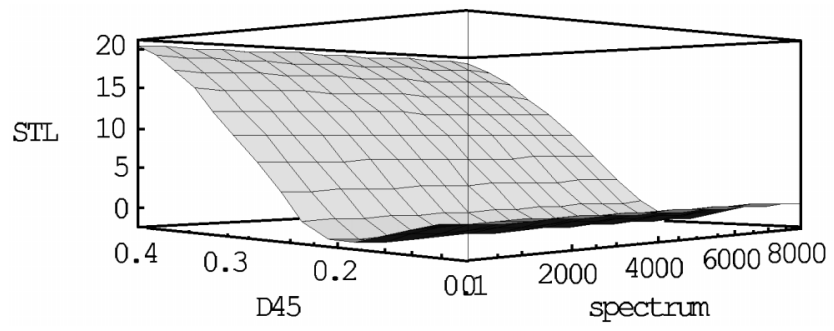

Fig. 6. STL with respect to frequency and D45. 
The shape constraints are $\frac{L_{3}}{D_{45}} \geq 2.46 ; L 2 \geq 0$

Originally, the initial design data of L3 is assumed to be 0.3 . To find out the numerical design data, three kinds of search algorithms used in the optimal design process are carried out and briefly introduced as follows.

\section{(A) Exterior penalty function method [7]}

The algorithm of exterior penalty function method is shown in Figure 9. Using exterior penalty function method, $\Phi$ is defined as

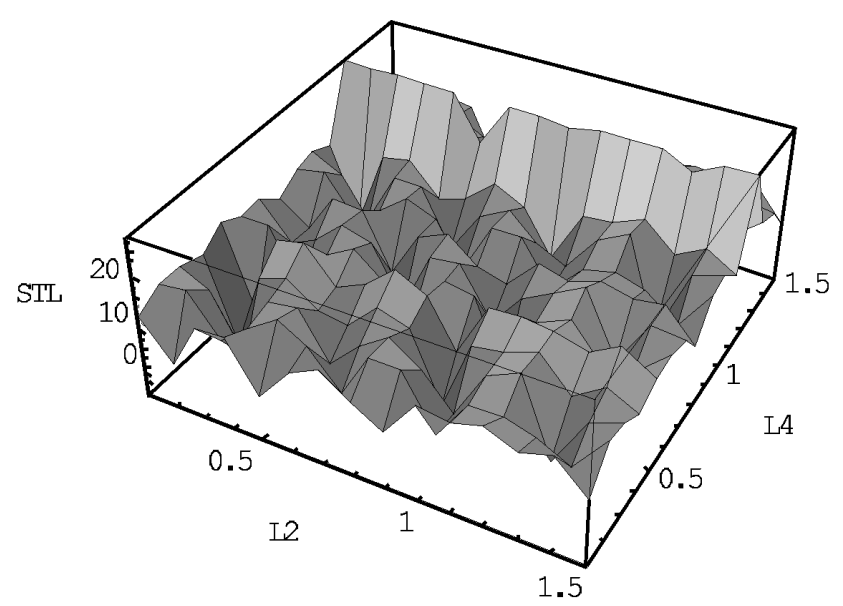

(a)

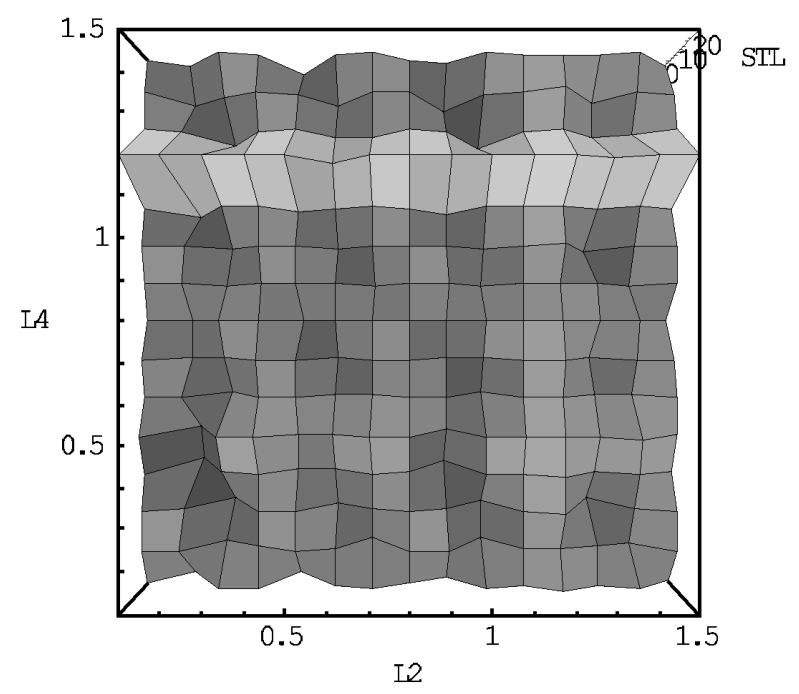

(b)

Fig. 7. (a) 3-D's STL with respect to $L 2$ and $L 4[D 1=0.0762$, D2 $=$ $0.0762, \mathrm{D} 45=0.3, \mathrm{~L} 1=0.1, \mathrm{~L} 2+\mathrm{L3}+\mathrm{L} 4=3.0]$; (b) 2-D's STL with respect to $\mathrm{L} 2$ and $\mathrm{L} 4[\mathrm{D} 1=0.0762, \mathrm{D} 2=0.0762, \mathrm{D} 45=$ $0.3, \mathrm{~L} 1=0.1, \mathrm{~L} 2+\mathrm{L3}+\mathrm{L} 4=3.0]$
$\Phi\left(X, r_{p}\right)=F(X)+r_{p} * P(X)=F(X)+r_{p} \sum_{i=1}^{2}\left\{\max \left[0, g_{i}(X)\right]\right\}^{2}$

where $g_{1}(X)=-X_{1} ; g_{2}(X)=-1.062+X_{1}$

(B) Interior penalty function method [7]

The algorithm of interior penalty function method is shown in Figure 10. Using interior penalty function method, $\Phi$ is defined as

$$
\Phi\left(X, r_{p}^{\prime}, r_{p}\right)=F(X)+r_{p}^{\prime} \sum_{j=1}^{2} \frac{-1}{g_{j}(X)}
$$

STL

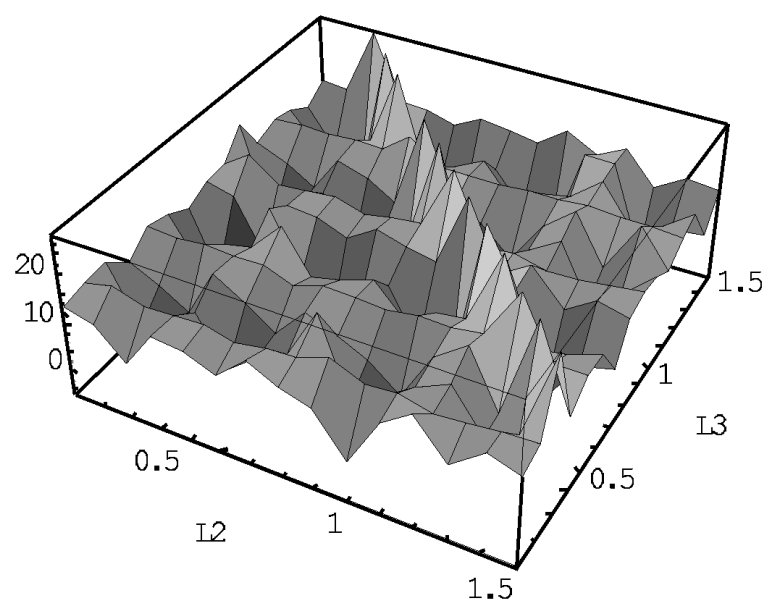

(a)

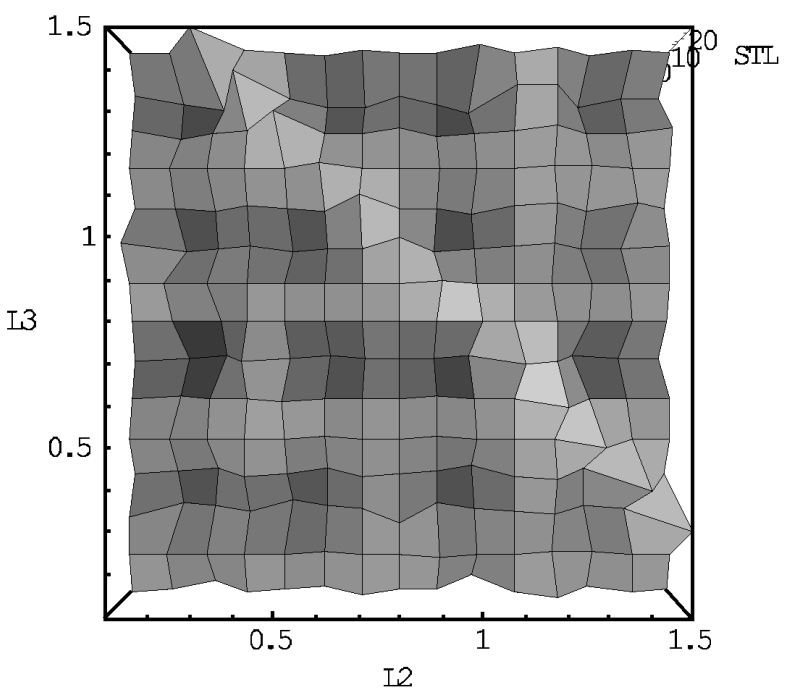

(b)

Fig. 8. (a) 3-D's STL with respect to $L 2$ and $L 3[D 1=0.0762, D 2=$ 0.0762, D45 = 0.3, L1 = 0.1, L2 + L3 + L4 = 3.0]; (b) 2-D's STL with respect to $\mathrm{L} 2$ and $\mathrm{L} 3[\mathrm{D} 1=0.0762, \mathrm{D} 2=0.0762, \mathrm{D} 45=$ $0.3, \mathrm{~L} 1=0.1, \mathrm{~L} 2+\mathrm{L3}+\mathrm{L} 4=3.0]$ 
where $g_{1}(X)=-X_{1} ; g_{2}(X)=-1.062+X_{1}$

\section{(C) Method of feasible direction [7]}

The search proceeds from one constraint to another in a zig-zag manner until the optimum is located. The algorithm of feasible direction method is shown in Figure 11. A tendency of this method is to zig-zag between the constraints.

\section{Iteration and Results}

Taking the initial design data as first trial value, a successive iteration together with the search algorithms such as interior penalty function method, exterior penalty function method and method of feasible direction are to be carried out individually. The optimal STL with respect to the optimal design parameters with the three methods are listed and shown in Table 2. The three sets of design data are found the same at $\{\bar{X}\}_{1}=(\bar{X})_{2}=(\bar{X})_{3}$ $=(0.171587)$. The complete design data are thus obtained and described as below.

$\mathrm{D} 1=0.0762(\mathrm{~m}) ; \mathrm{D} 2=0.0762(\mathrm{~m}) ; \mathrm{L} 1=0.1(\mathrm{~m}) ;$ $\mathrm{D} 45=0.3(\mathrm{~m}) ; \mathrm{L} 5=0.1(\mathrm{~m}) ; \mathrm{L} 2=0.171587(\mathrm{~m}) ; \mathrm{L} 3=$ $1.628413(\mathrm{~m}) ; \mathrm{L} 4=1.2(\mathrm{~m})$

From Table 2, it is observable that both results are identical. The STL of muffler are calculated as $192 \mathrm{~dB}$ simultaneously. Using the design data, the profile of STL with respect to frequency domain is illustrated in Figure 12. A comparison of diesel engine's noise spectrums with and without muffler is shown as Figure 13. It is also found that the effect of noise reduction at $500 \mathrm{~Hz}$ is satisfactorily acceptable.

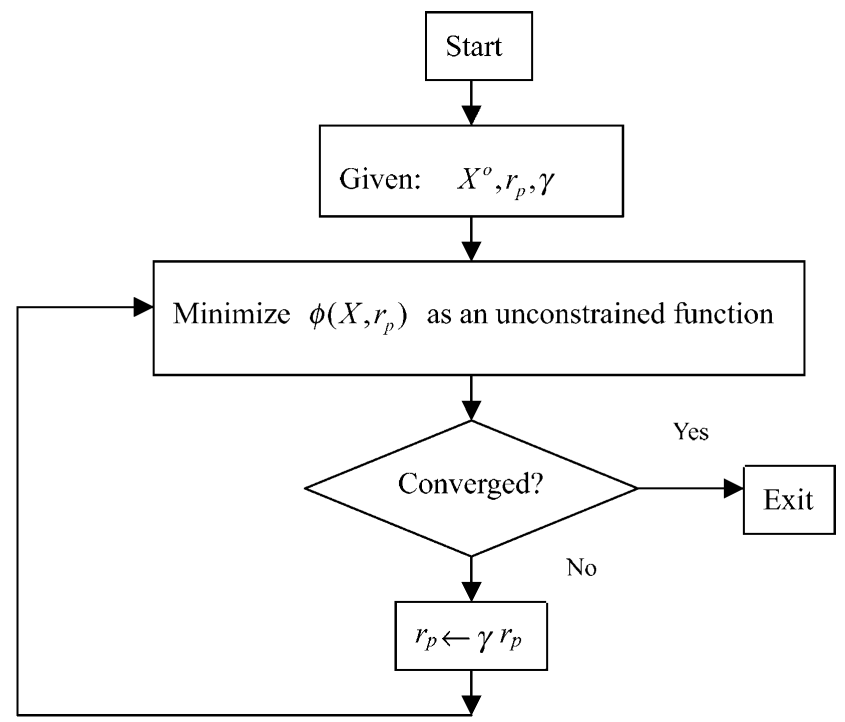

Fig. 9. Algorithm of exterior penalty function method [7].

\section{Accuracy}

To ensure the optimality of L2, L3, and L4 with constraint relationship of $\mathrm{L} 2+\mathrm{L} 3+\mathrm{L} 4=\mathrm{Lo}$, the final convergence criterion, Kuhn-Tucker Condition [7], was used and described as follows.

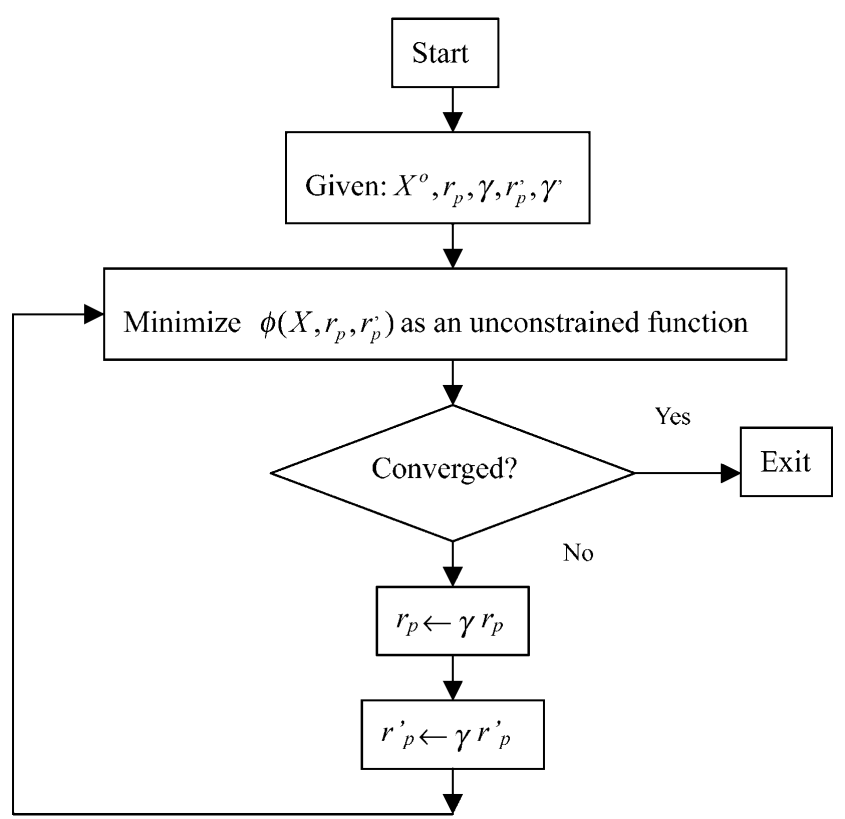

Fig. 10. Algorithm of interior penalty function method [7].

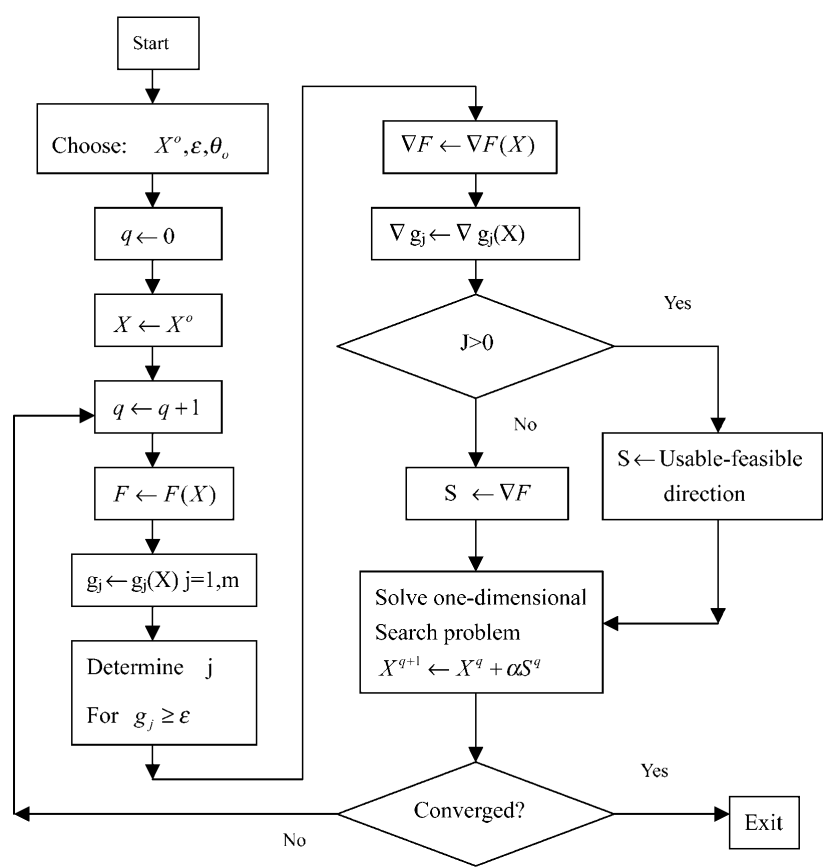

Fig. 11. Algorithm of method of feasible direction [7]. 


$$
\begin{aligned}
& \lambda_{j} g_{j}\left(X^{*}\right)=0, j=1,3, \lambda_{j} \geq 0 \\
& R\left(X^{*}\right)=\nabla F\left(X^{*}\right)+\sum_{j=1}^{2} \lambda_{j} \nabla g_{j}\left(X^{*}\right)
\end{aligned}
$$

To meet the converge criterion, the conditions of $R$ $\left(X^{*}\right) \approx 0 \lambda_{j} \geq 0$ are required.

Where $\lambda_{j}$ : Vector of Lagrange multiplier

$\nabla F\left(X^{*}\right)$ : Function Gradient Vector

$R\left(X^{*}\right)$ : Residual Vector

Introducing $\{\bar{X}\}_{1}$ into Kuhn-Tucker Condition, the results are then shown in Table 3. It's found the residual vector is close to zero and matches the KuhnTucker Condition

\section{CONCLUSIONS}

In this paper, the theoretical STL of muffler with side inlet/outlet tube is deduced, a computer graphic system for quick examination of all the global peak points is presented, and the decisions of sensitivity analysis for each design parameter are achieved. According to the graphic analysis on sensitivity, one set of design data is primarily determined from chart. Using the fundamental data as the initial design value, three kinds of searching techniques are then processed, and the more accurate solutions can therefore be composed. Moreover, the Kuhn-Tucker Condition is then applied to verify the accuracy of the solution.

This study definitely offers a simple progress to not only organize the optimum design in muffler, but also compromise the effective for the constraint problem which is frequently occurred in a basement or other buildings. Through the case study presented, the optimal design in muffler for STL at $500 \mathrm{~Hz}$ is found accurate by using the confirmation of Kuhn-Tucker situation. This study absolutely provides the economi-

Table 2. Optimal STL with respect to the optimal design parameters in three methods

\begin{tabular}{cccc}
\hline Method & L2 & L3 & STL \\
\hline Exterior Penalty Function Method & 0.171587 & 1.628413 & 191.9 \\
Interior Penalty Function Method & 0.171587 & 1.628413 & 191.9 \\
Feasible Direction Method & 0.171587 & 1.628413 & 191.9 \\
\hline
\end{tabular}

Table 3. Results of Kuhn-Tucker Condition's checking process in three methods

\begin{tabular}{cccccc}
\hline Method & \multicolumn{3}{c}{ Lagrange Multipliers } & \multicolumn{3}{c}{ Residual Vector } \\
& $\lambda_{1}$ & $\lambda_{2}$ & $\lambda_{3}$ & $\left\{R_{1}\right\}$ & $\left\{R_{2}\right\}$ \\
\hline Exterior Penalty Function Method & 3323.3 & 64703.5 & 4813.8 & 0.0 & 0.0 \\
Interior Penalty Function Method & 3323.3 & 64703.5 & 4813.8 & 0.0 & 0.0 \\
Feasible Direction Method & 3323.3 & 64703.5 & 4813.8 & 0.0 & 0.0 \\
\hline
\end{tabular}

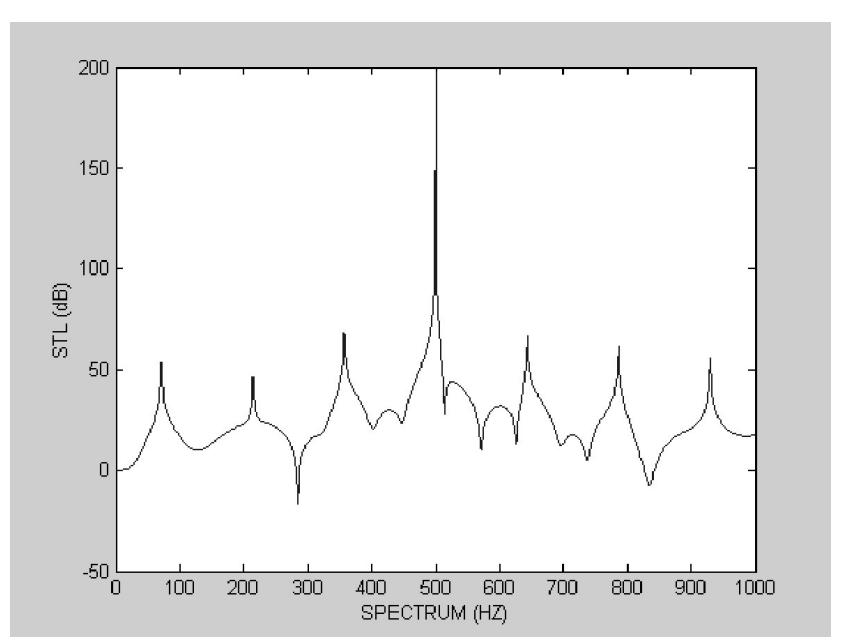

Fig. 12. STL with respect to frequency.

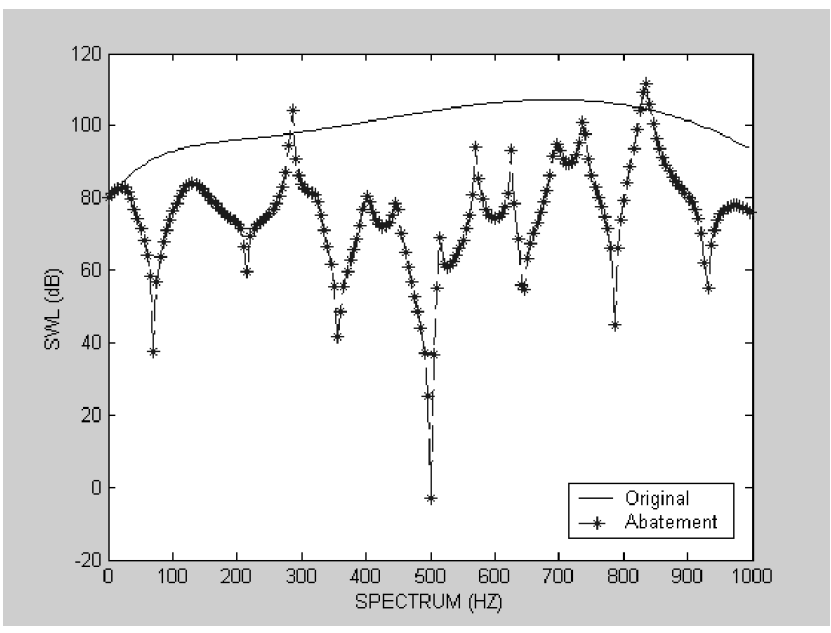

Fig. 13. Predicted spectrum curves of noise level with and without adding muffler. 
cal approach to optimize the design for a single-chamber muffler with side inlet/outlet under space constraints without redundant testing.

\section{NOMENCLATURE}

$\rho_{o} \quad$ air density $\left(\mathrm{kg} \mathrm{m}^{-3}\right)$

$\gamma \quad$ specific heat ratio of air

$C_{o} \quad$ sound speed $\left(\mathrm{m} \mathrm{s}^{-1}\right)$

$D_{i} \quad$ diameter of the ith duct (m)

$j \quad \sqrt{-1}$

$k \quad$ wave number.

$L_{i} \quad$ length of the ith duct (m)

$M_{i} \quad$ mean flow Mach number at $i$

$P \quad$ total flow pressure $(\mathrm{Pa})$

$p_{i} \quad$ acoustic pressure at $i(\mathrm{~Pa})$

$r_{p} \quad$ penalty parameter

$r_{p}^{\prime} \quad$ penalty parameter

$S_{i} \quad$ section area at $i\left(\mathrm{~m}^{2}\right)$

STL sound transmission loss (dB)

$S W L$ sound power level $\left(\mathrm{dB}\right.$ re $\left.10^{-12} \mathrm{~W}\right)$

$u_{i} \quad$ acoustic particle velocity at $i\left(\mathrm{~m} \mathrm{~s}^{-1}\right)$

$V \quad$ total flow velocity $\left(\mathrm{m} \mathrm{s}^{-1}\right)$

$V_{i} \quad$ mean flow velocity at $i\left(\mathrm{~m} \mathrm{~s}^{-1}\right)$

$v_{i} \quad$ acoustic mass velocity at $i\left(\mathrm{~kg} \mathrm{~s}^{-1}\right)$

$\omega$ radian frequency

$Y_{i} \quad$ characteristic impedance at $i$

$Z_{i} \quad$ impedance at $i$

\section{REFERENCES}

1. Bernhard, R.J., "Shape Optimization of Reactive Mufflers," Noise Control Engine. J., Vol. 27, No. 1, pp.
10-17 (1986).

2. Munjal, M.L., Acoustics of Ducts and Mufflers with Application to Exhaust and Ventilation System Design, John Wiley and Sons, New York, pp. 58-59 (1987).

3. Munjal, M.L., "Plane Wave Analysis of Side Inlet/ Outlet Chamber Mufflers with Mean Flow," Appl. Acoust., Vol. 52, pp. 165-175 (1997).

4. Munjal, M.L. and Prasad, M.G., "Transfer Matrix of a Uniform Tube with Moving Medium and Linear Temperature Gradient.," J. Acoust. Soc. Am., Vol. 80, No. 50, pp. 1501-1506 (1986).

5. Prasad, M.G., "A Note on Acoustic Plane Waves in a Uniform Pipe with Mean Flow," J. Sound Vibra., Vol. 95, No. 2, pp. 284-290 (1984).

6. Prasad, M.G. and Crocker, M.J., "Studies of Acoustical Performance of a Multi-cylinder Engine Exhaust Muffler System,” J. Sound Vibra., Vol. 90, No. 4, pp. 491508 (1983).

7. Vanderplaats, G.N., Numerical Optimization Techniques for Engineering Design: With Applications, McGrawHill, New York, pp. 71-195 (1984).

8. Yeh, L.J., Chiu, M.C., and Lay, G.J., "Computer Aided Design on Single Expansion Muffler under Space Constraints," Proceedings of the $19^{\text {th }}$ National Conference on Mechanical Engineering (The Chinese Society of Mechanical Engineers), Hu-wei, Taiwan, C7, pp. 625633 (2002). 